Document downloaded from:

http://hdl.handle.net/10251/66241

This paper must be cited as:

Serrano Cruz, JR.; Guardiola, C.; Dolz García, VM.; López, M.; Bouffaud, F. (2015). Study of the turbocharger shaft motion by means of infrared sensors. Mechanical Systems and Signal Processing. 56-57:246-258. doi:10.1016/j.ymssp.2014.11.006.

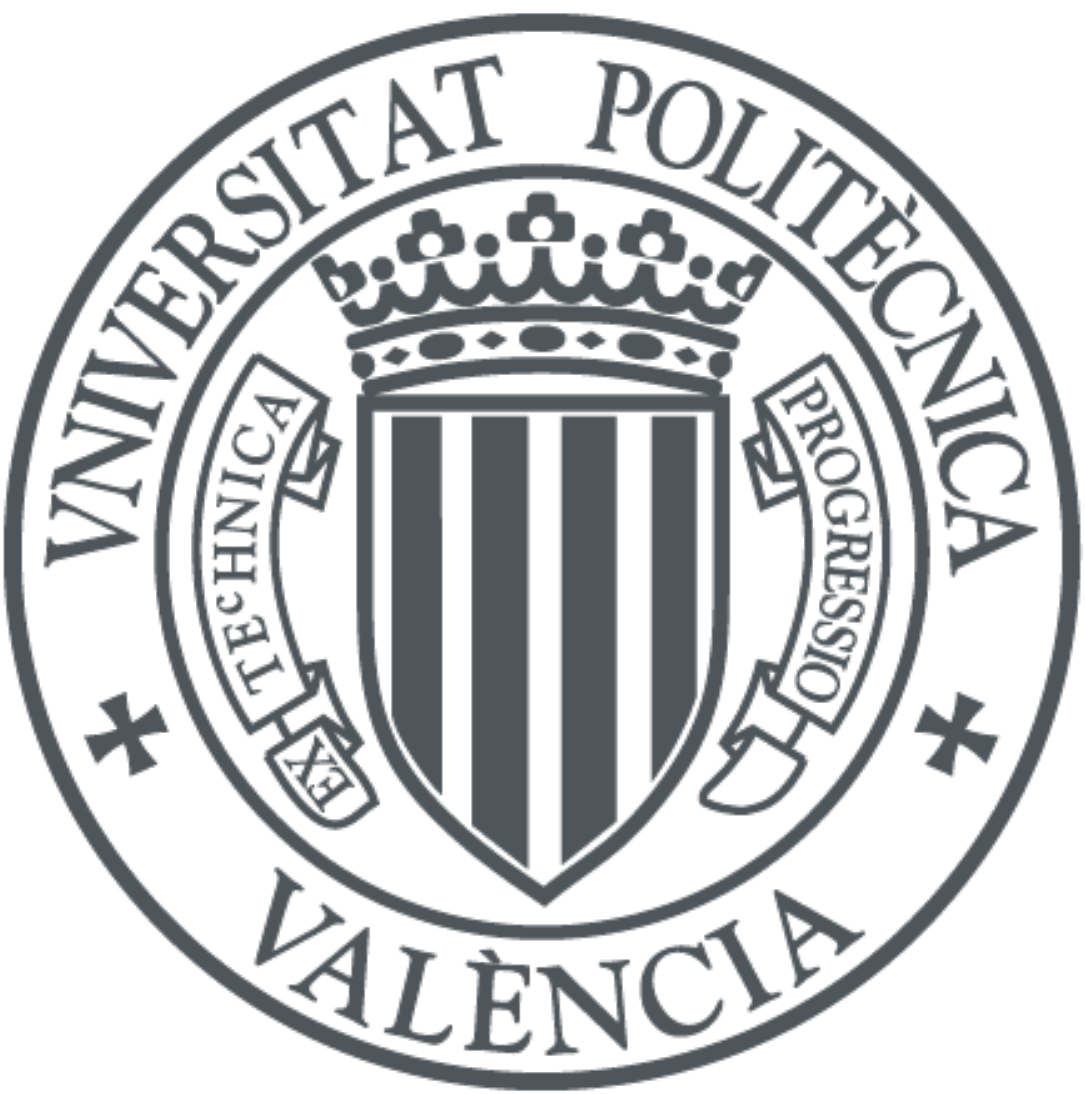

The final publication is available at

http://dx.doi.org/10.1016/j.ymssp.2014.11.006

Copyright Elsevier

Additional Information 


\title{
Study of the turbocharger shaft motion by means of infrared sensors
}

\author{
JR Serrano $^{\text {a }}$, C. Guardiola ${ }^{\text {a }}$, V Dolz $^{\text {a, * }}$, MA López ${ }^{\text {a }}$, F Bouffaud ${ }^{\text {b }}$ \\ ${ }^{a}$ CMT - Motores Térmicos, Universitat Politècnica de València, Spain \\ ${ }^{\mathrm{b}}$ RSA - Renault SA, France
}

Keywords: Turbocharger, Lubrication, Bearing, Shaft motion, Infrared, Synchronous.

\begin{abstract}
This work describes a technique for measuring the precession movement of the shaft of small automotive turbochargers. The main novelty is that the technique is based on infrared light diode sensors. With presented technique it is possible to perform secure mounting of electronics and also to measure, with good accuracy, far enough from the turbocharger shaft. Both advantages allow applying it even in critical lubrication conditions and when blade contact events. The technique main difficulties arise from the small size of the turbocharger shaft and the high precession movement in critical conditions. In order to generate the optimum albedo reflection for infrared measurement, a special cylindrical nut with larger diameter than the original one is assembled at the shaft tip in the compressor side. Following, shaft balancing, the calibration of the sensors and the compensation of errors from different sources are needed steps before the method is able to identify the main frequencies of shaft motion. Once synchronous and sub-synchronous frequencies have been obtained it is possible to reconstruct the instantaneous position of the shaft to determine its precession movement.
\end{abstract}

\section{INTRODUCTION}

The trend of internal combustion engines (ICE) is to improve efficiency, to fulfill the anti-pollution regulations, which are becoming more restrictive, and to maintain a

\footnotetext{
* Corresponding author. Tel.: +34 963877650; Fax: +34 963877659.

Camino de Vera s/n, 46022 Valencia, Spain

E-mail address: vidolrui@mot.upv.es (V. Dolz).
} 
power output that meets current user demand [1]. In this context, there are several studies and new technological proposals [2] [3] [4] [5]. However, the most successful technique because of its "easy matching" and "noninvasive coupling" is boosting with turbochargers [6] [7] [8] thus complying with trends mentioned above.

The efficiency and proper performance of a turbocharger can be affected by several external causes. Some of these causes have been studied experimentally such as foreign objects entering the compressor [9], cuts in lubrication [10], mechanical friction losses [11]. Moreover, there are different models that helped to know different aspects of the turbocharger performance: vibrations models [12] [13], numerical models of the air flowing through the volute [14] and models to control the turbocharger flow [15].

An important variable that affects the turbocharger behavior is the precession movement of the shaft. It is a complex phenomenon which depends on effects such as:

a) Hydrodynamic lubrication of the bearings. Most turbochargers use floating and semi-floating bearings, in both cases, there is a phenomenon called oil whirl/whip, which is based on the self-excited vibrations caused by the lubrication film [16].

b) Rotating shaft modes. They depend directly on the shaft speed and its deformation, and they include: conical, translational, torsional and bending deformations [17] and each of these can spin into a forward (FW) or a backward (BW) movement.

c) Imbalances. Small turbochargers can spin at high speeds (230krpm or more) and a small imbalance can produce large vibrations [18] [19].

Different techniques have been developed to measure the shaft movement, such as inductive sensors [20], laser Doppler vibrometers [21], laser Doppler distance sensors [22] and photo sensing resistor [23], these three last techniques have been applied in larger shafts, which is not the case in present work. In small turbochargers with smaller shafts and high turbo speeds only inductive sensors [20] have been reported in the literature.

The assembly in the three previous cases is much more complex than the system described in this paper. In these three cases, optical access is required through the turbocharger bearing housing and the sensors are installed outside of the turbocharger and the accuracy of the measured will be affected by the relative movements between the turbocharger and the sensors (vibration). While, in the technique described in this article, the sensors can be installed directly in the compressor case inlet, pointing to the edge of the shaft. This is a great advantage in passenger car turbochargers as they are very compact and they present a complex access to the shaft. A further disadvantage of the above three cases is that the electronics are attached to the sensor and usually the electronic not support extreme temperatures, making it difficult to test the turbocharger at very high or very low temperatures.

On the other hand, the main advantage of the described technique with respect the inductive sensors is that the infrared light diode sensors can be installed at distances higher than $2 \mathrm{~mm}$ from the shaft of the turbocharger and they present a good accuracy. It is an ideal characteristic for measuring during destructive tests. 
In the present paper the precession movement is studied by means of optical infrared sensors. The infrared sensors have been applied in the measurement of the shaft motion and position of blades in large shafts [24][25][26]; however there are no previous works covering the use of this type of sensors for the measurement of the precession movement in small size turbochargers, as those used for ICE boosting.

To perform this technique, a cylindrical nut on the shaft tip at compressor side was installed. This cylindrical nut was used to have an area big enough to reflect the infrared light.

In order to simplify the analysis of the results of this article, the deformations of the shaft will not be considered, because measuring these deformations requires measurements in different points along the shaft and only measurements in the shaft tip have been performed. Therefore, the present work is limited to measure rotational orbits described by the tip of the shaft.

The paper is structured as follows: section 2 presents the experimental layout and the technique for sensors calibration; section 3 presents the proposed measurement methodology, with details on procedure and data processing approach; section 4 presents an application example, where the described methodology is used for studying the acceleration of a turbocharger during a turbocharged ICE tip in. Finally, conclusions are presented in section 5 .

\section{TEST BENCH LAYOUT \& SENSOR CALIBRATION}

In order to measure the position of the shaft, two infrared light diode sensors have been placed in a radial position at the compressor side (hereinafter sensor 1 and sensor 2), pointing to the tip of the shaft and forming together an angle of $90^{\circ}$, Table 1 shows the main characteristics of the sensors. To minimize the opening of the light beam after reflection, a cylindrical nut of Titanium with a large diameter of about $12 \mathrm{~mm}$ is placed in the tip of the compressor shaft. Furthermore the surface of this cylinder has been painted with a matte white color to get an albedo that maximizes the reflection of infrared light, with the objective of increasing the sensitivity of the sensors. Figure 1 shows a scheme of the described system. 


\begin{tabular}{|c|c|}
\hline \multicolumn{2}{|c|}{ TECHNICAL SPECIFICATIONS } \\
\hline RANGE & RECOMMENDED RANGE \\
\hline Diffuse Reflection & $0,5 \mathrm{~mm}<\mathrm{D}<10 \mathrm{~mm}$ (black and white encoders) \\
\hline Through-beam & $>30 \mathrm{~mm}$ \\
\hline \multicolumn{2}{|l|}{ ELECTRICAL SPECIFICATIONS } \\
\hline Transmitter & Diode E.L IR. + visible \\
\hline Receiver (light sensitive) & Fast semiconductor \\
\hline Output/Nature of signal/ Cable outlet $1 \mathrm{M}^{*}$ & TTL PNP $5 \mathrm{Vcc}+$ Analogue from $500 \mathrm{mV}$ to $5 \mathrm{Vcc}$ \\
\hline Supply/ operating voltage by separate cable & $12 / 24 \mathrm{Vcc}$ \\
\hline Current consumption & $120 \mathrm{~mA}$ with $12 \mathrm{~V}$ \\
\hline Connection & $3 \times 1 \mathrm{~m}$ caqbles: $2 \mathrm{BNC}+1$ cable \\
\hline $\begin{array}{l}\text { Frequency/ receiver theoratical response time } \\
\text { (measured from } 20 \% \text { to } 85 \% \text { of signal) }\end{array}$ & $\begin{array}{l}\mathrm{F}>1 \mathrm{Megahertz} / \text { Rise time }=\text { Fall time }<35 \\
\text { nanosec. }\end{array}$ \\
\hline Temperature, max. Internal (dry conditions) & from $-10^{\circ} \mathrm{C}$ to $+50^{\circ} \mathrm{C}$ \\
\hline Temporary electrical protection & Yes \\
\hline \multicolumn{2}{|l|}{ MECHANICAL SPECIFICATIONS } \\
\hline Box & AU4G anodized, standard in gold \\
\hline Mass & $<160 g$ \\
\hline Shape \& setting & $14 \times 48 \mathrm{~mm}, 4 \times \varnothing 3 \mathrm{~mm}$ \\
\hline \multicolumn{2}{|l|}{ OPTICAL PROBES } \\
\hline Through-beam probes/ slit ending fibre probe & Multi FFO Multi SLIT FFO \\
\hline Diffuse Reflection / slit ending fibre probes & MultiYO Multi SLIT YO \\
\hline Temperature range for standard optical probes & from $-50^{\circ} \mathrm{C}$ to $+120^{\circ} \mathrm{C}$ \\
\hline Integrated optics & Micro optic \\
\hline
\end{tabular}

Table 1 Characteristics of the Infrared light diode sensor

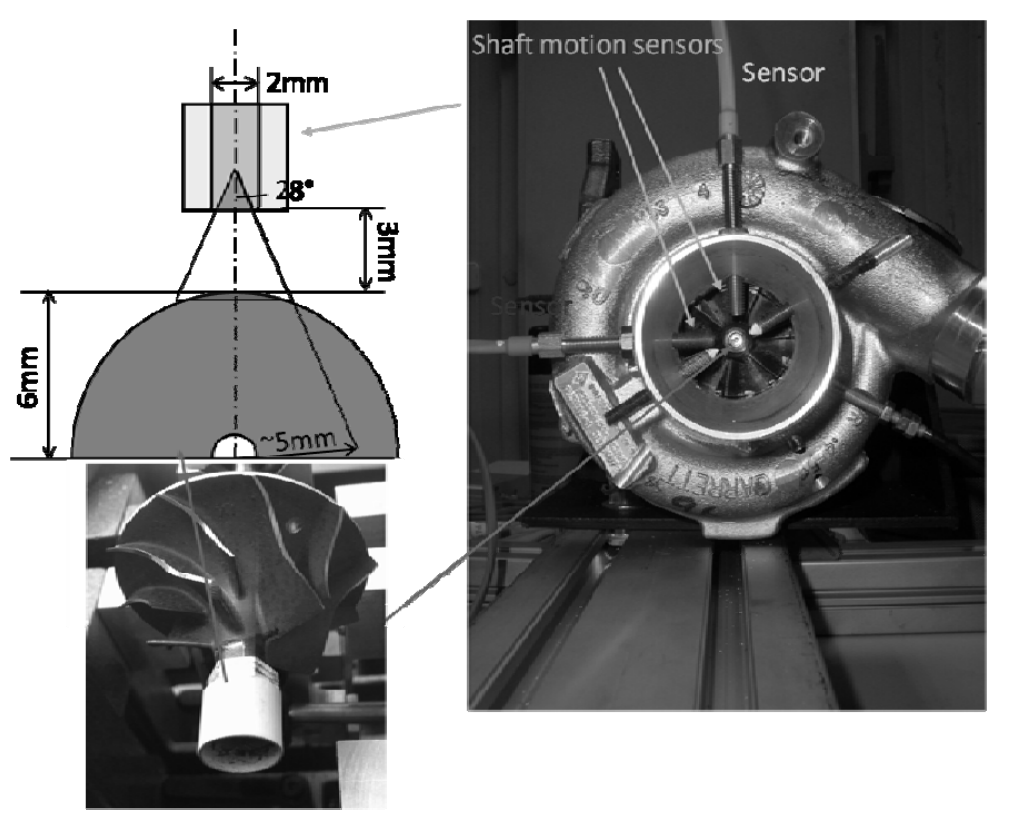

Figure 1 Scheme of the infrared light diode sensors setup

The sensors used are placed with a $3 \mathrm{~mm}$ gap, approximately, between the tip of the sensor and the surface of the cylindrical nut assembled to the shaft (Figure 1). These sensors have operative ranges between $0.5 \mathrm{~mm}$ and $10 \mathrm{~mm}$ and are able to record data at 
frequencies up to $1 \mathrm{MHz}$. However, to avoid memory problems in the recording of the data, the acquisition frequency was set to a high enough frequency of $100 \mathrm{kHz}$.

The calibration curves of the sensors are determined using a positioning table and a micrometer. This device allows moving the sensor radially to the axis of the modified turbocharger shaft. Thus, the sensor can be positioned at different distances from the cylindrical nut, in order to determine the ratio between the voltage obtained by the electronic device of the sensor and the distance from the tip of the sensor to the surface of the cylindrical nut. This calibration arrangement has been also used to estimate the sensibility of the sensors. Figure 2 shows the result of such sensibility study for distances around to $3 \pm 0.5 \mathrm{~mm}$, which is range of distance at which they are placed during the experiments. The curves of the two sensors show a good repeatability between the measured voltage and the distance to the cylinder surface. Figure 2 also shows the dispersion between different sets of measurements. It provides a maximum standard deviation uncertainty of about $0,017 \mathrm{~V}$.
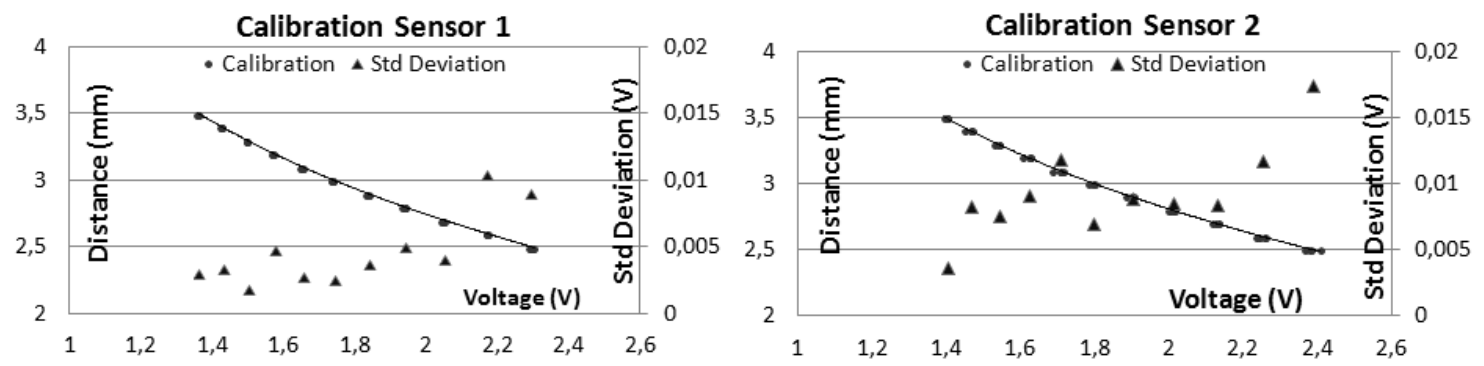

Figure 2 Calibration curves of the two infrared light diode sensors

The modified shaft is balanced in a machine with two Y-shaped supports and two strain gauges, which estimate the unbalancing of the shaft. A belt and an electric motor produce the rotation movement to determine shaft unbalancing. The arrangement to calibrate the sensors, previously described, is also mounted in the balancing machine. Figure 3 shows the equipment for balancing the shaft with the assembled cylinder and the arrangement to calibrate the optical sensors. 

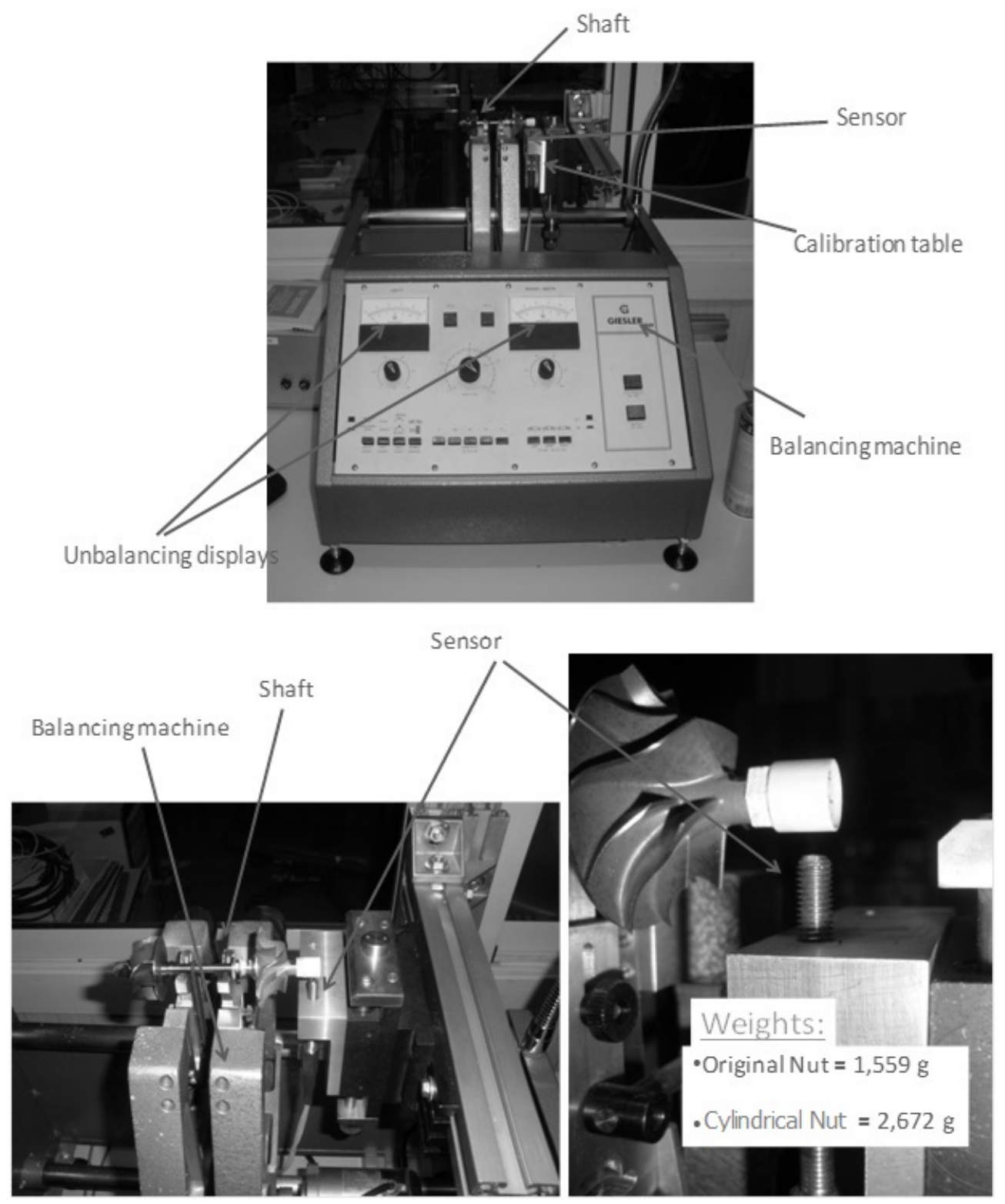

Figure 3 Installation to balance the shaft and to calibrate the sensors

When the shaft has been balanced and the sensors have been calibrated, the modified shaft and the sensors are assembled on the turbocharger and it is installed in an engine coupled to a test bench. The engine test bench allows testing the turbocharger in both normal and abnormal operative conditions, in order to reproduce special situations as for example failures of lubrication, surge limit operative conditions, over speed, etc. 


\section{SHAFT MOTION MEASUREMENT METHODOLOGY}

To estimate the shaft motion, a methodology with three different tasks has been defined: the reduction of the error sources, the estimation of the maximum eccentricity and the identification of the synchronous and sub-synchronous frequencies

\subsection{Reduction of the error sources}

Several tests have been performed to detect and analyze the different error sources with the optical technique used in this paper:

\subsubsection{Errors due to the measuring instrument}

- Error associated to sensor alignment: The sensors must be perfectly perpendicular to the axis of the turbocharger shaft, in order to optimize the obtained measurements. Moreover, the axis of the two sensors must be positioned at $90^{\circ}$ and must be placed in a plane perpendicular to the shaft axis. The position variations of the sensors with respect to these specifications can introduce errors in the obtained results to estimate the position of the shaft. In order to minimize these errors, the sensor calibration has been done with the sensor assembled to the turbocharger and several tests have been performed to observe the repetitiveness of the measurement. Figure 4 shows a scheme with different alignments (angular positions) of the sensor. The right graph of this figure shows the voltage of a sensor for a given distance $(6 \mathrm{~mm})$. In these sensors, the voltage depends on the distance; however the voltage can also change due to the alignment. If the angular position increases, the voltage decreases. It doesn't have a relevant dispersion with the angles $0^{\circ}$ and $2^{\circ}$ (square and triangle in the Figure 4), but with the angles $4^{\circ}$ and $5^{\circ}$ (circle and diamond in the Figure 4), it has a ratio of $0.01 \mathrm{v} / 1^{\circ}$.

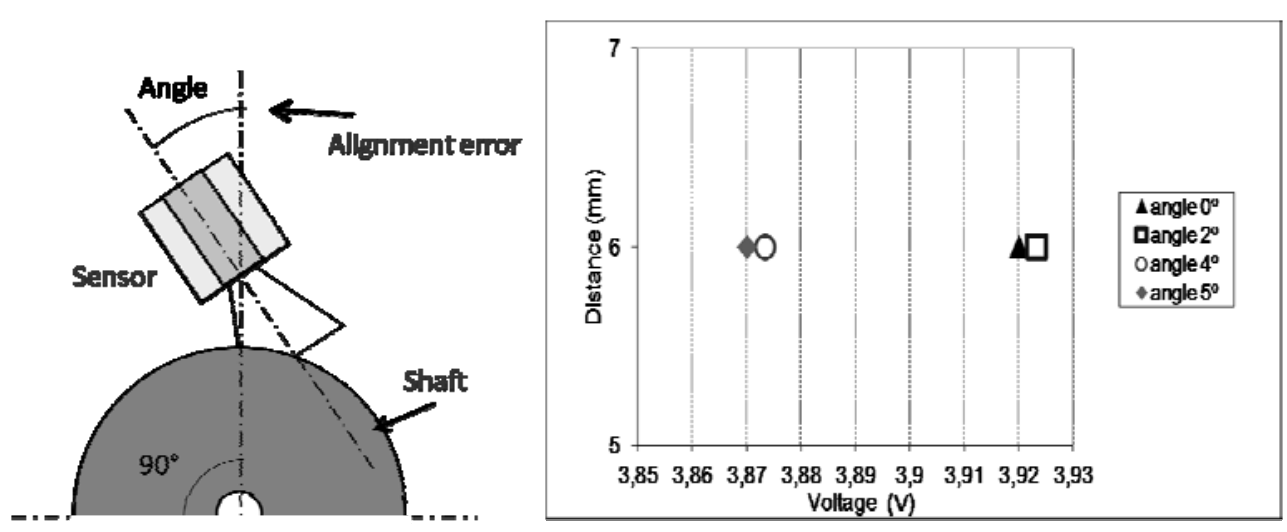

Figure 4 Alignment errors in different angular position sensor 
- Error associated to sensor wear: The optical fiber is very sensitive to the manipulation and torsional efforts can cause a loss of the fiber effective area. In order to minimize this error, the final sensor calibration is done with the sensor assembled to the turbocharger. In addition, before each measurement, it should be checked the voltage at a known distance to verify the signal offset deviation. Figure 5 shows an example of this type of error; it shows the measurements of a sensor in different days but in the same relative position between the shaft and the sensor. In the first day " $12 / 04 / 2012$ ", the average of the sensor signal is near $1.95 \mathrm{~V}$. In following days, the voltage signal provided by the sensor is reduced due to the wear of the optical fiber and the average of the signal changes to $1.675 \mathrm{~V}$ approximately.

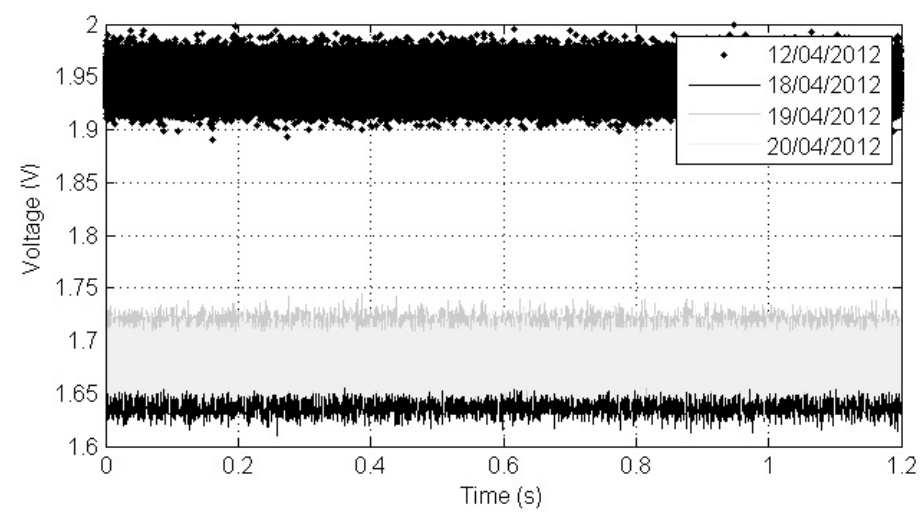

Figure 5 Deviation in the signal of an infrared light diode sensor

- Error associated to surface properties: The surface color of the cylindrical nut could change the infrared light reflection (surface albedo) and consequently, the results of the measurements. A short study of surface color was conducted to analyze this error. Figure 6 shows the differences in sensor voltage between a matte white colour surface and a brushed metal surface when the sensor tip is displaced from nut surface to $4 \mathrm{~mm}$ distance. Figure 6 shows that matte white painted surface has less dispersion and this is why it is recommended for this experimental technique.

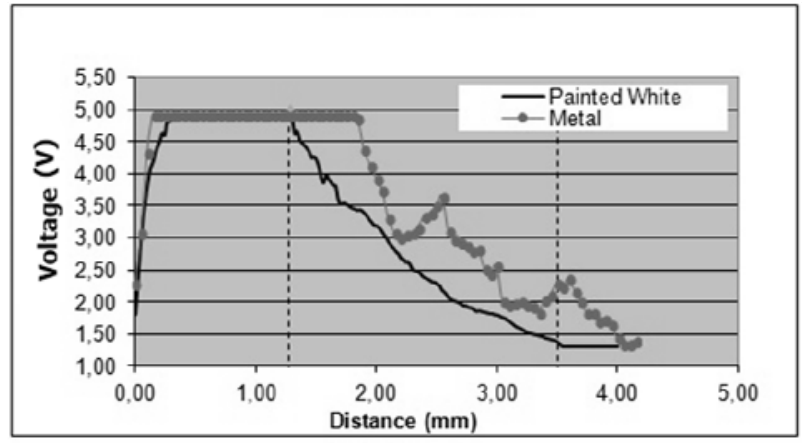

Figure 6 Calibration of sensors in different coloured surface 


\subsubsection{Errors due to ambient sources}

- Errors due to external light sources: One can think in two types of unwanted light sources that can be captured by the infrared fiber of the sensor: the infrared ambient light, which doesn't come from the sensor, and the reflections of sensor light from other surfaces than the cylindrical nut. To avoid first effect, the external light sources have been minimized and kept constant during calibration and testing. Concerning the error of other reflections of surfaces, it was not detected a significant effect.

- Errors due to electromagnetic fields: Electromagnetic fields in the test room can introduce errors into the sensor signal and in the electronic devices. Before testing, the sensors signal with the shaft stopped is recorded to determine the noise and subtract it from the measured signals. Figure 7 shows the FFT signal of the sensors with the turbocharger stopped and consequently no relative movements between shaft and sensors. The signal of sensor 1 shows a relevant electromagnetic induction at $1750 \mathrm{~Hz}$ and sensor 2 at around $600 \mathrm{~Hz}$ has an electromagnetic induction of similar magnitude.
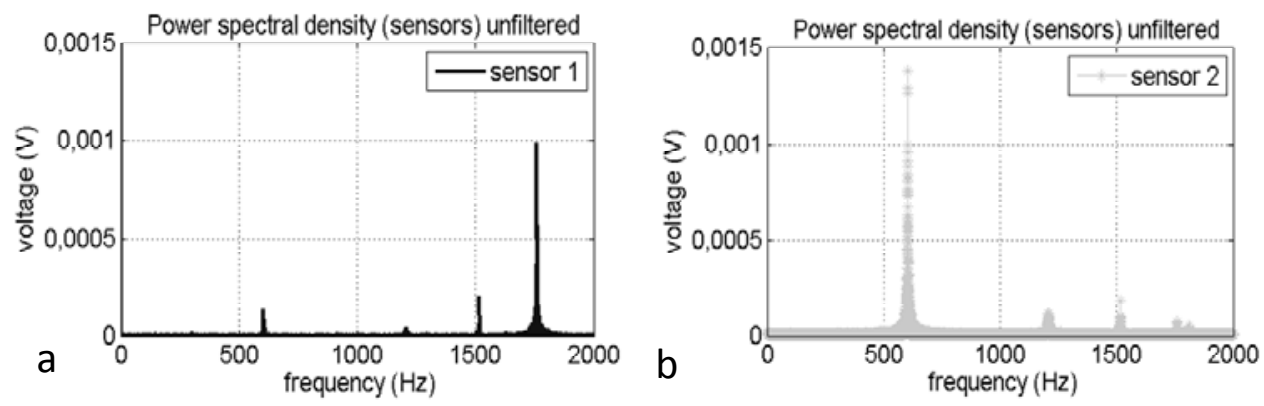

Figure 7 FFT signal with stopped shaft

- Errors due to temperature variations: High temperature variations could affect the level of the sensor signal, therefore calibration depends on the test room temperature. A study to determine this error was done in a climatic chamber with room temperature variation capability. During the experiment sensors were pointed to a fixed surface while chamber temperature was increased from $-10^{\circ} \mathrm{C}$ to $15^{\circ} \mathrm{C}$. Figure 8 shows the result of this test for sensor 1 and sensor 2 . Figure 8 shows that signal trends are not linear and each sensor has a different behavior. The calibration at $15^{\circ} \mathrm{C}$ was taken as the reference and it was corrected with the measured temperature variations according to the information from Figure 8. 


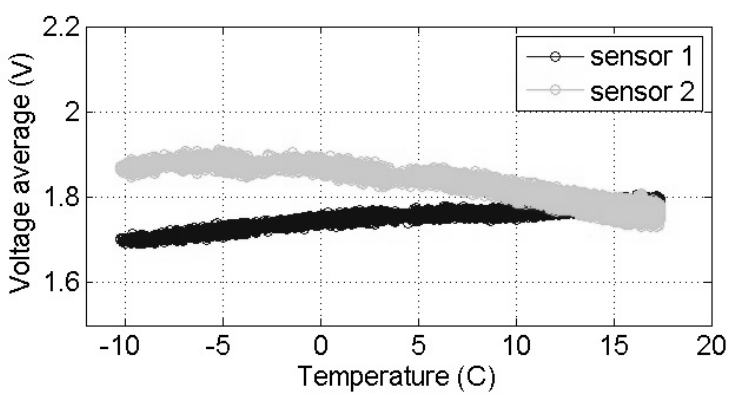

Figure 8. Effect of temperature variation in the signal

\subsubsection{Errors due to the geometric tolerance}

As it has been previously explained, the original shaft of the compressor eye has been replaced by a cylinder with a diameter of $12 \mathrm{~mm}$. So, another preliminary step previous to measuring the shaft motion with the infrared light diode sensors is to study the geometric tolerance of this modified shaft.

- Errors due to cylinder deformation: The deformation due to centrifugal forces of the cylindrical nut can introduce an error in the signal of the infrared light diode sensors. However, deformation calculations show negligible results and significant errors have not been detected due to deformation.

- Errors due to shape of the cylinder surface: The surface shape of the new compressor eye is not perfectly cylindrical, so it has influence on the measured signal. Figure 9 shows the frequency spectrum of the infrared light diode signal from five different measurements. These measurements show a very good repeatability. Experiments showed at Figure 9 were performed with the assembly (shaft plus cylindrical nut) perfectly balanced and in the balancing machine rotating at $2700 \mathrm{rpm}$, which is a very low speed. Figure 9 shows a big peak at $45 \mathrm{~Hz}$, which corresponds to the rotational speed of the shaft in the balancing machine (2700rpm). Considering that the whirl movement of the shaft assembly in the balancing machine is null, one can conclude that this peak and its multiples are due to imperfections in the surface of the cylindrical nut mounted on the compressor eye. This result is important because it represents an error in the measurement of the shaft position when the shaft is spinning and it must be subtracted in the raw signal captured by the sensors. Figure 9 shows that the synchronous peak is approximately $0.02 \mathrm{~V}$ high. This is the voltage subtracted from the raw signal captured by the sensors. 


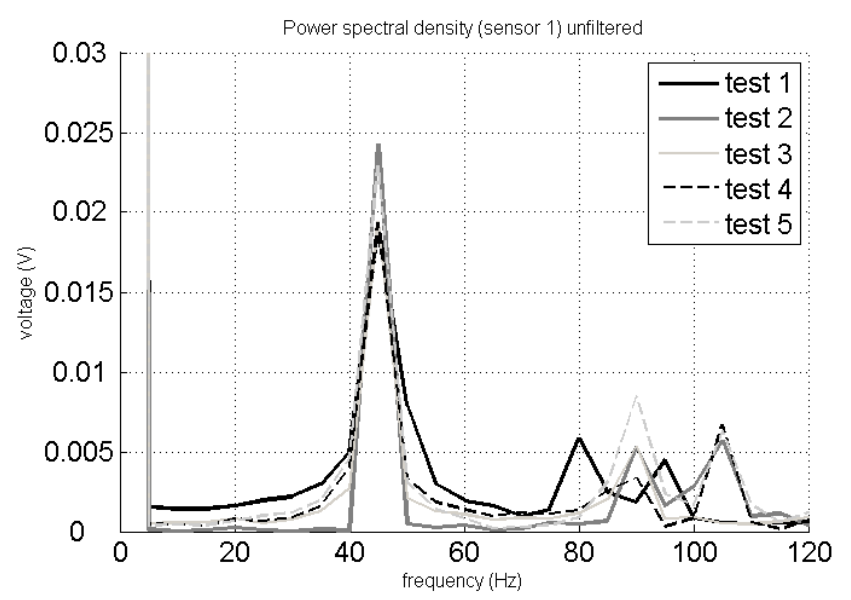

Figure 9 Repeatability study of the modified balanced shaft

Table 2 shows a summary of the parameters that can be quantified and the error voltage associated:

\begin{tabular}{|l|c|c|}
\hline \multicolumn{1}{|c|}{ Error Source } & Parameter of error & Voltage Sensor Error (V) \\
\hline Alignment sensor error & $0^{\circ}-5^{\circ}$ & $0-0,06$ \\
\hline Color surface & metal vs white painted & $0,34-1,41$ \\
\hline Temperature variations & from $-10^{\circ} \mathrm{C}$ to $15^{\circ} \mathrm{C}$ & 0,1 \\
\hline
\end{tabular}

Table 2 Order of magnitude of error sources and associated voltage errors.

\subsection{Maximum eccentricity}

The maximum eccentricity of the shaft has to be measured, as in methodologies described in other works [10], in order to establish a threshold for the shaft motion. The infrared light diode sensors can measure the position of the shaft while it is forced (by hand) to rotate in a maximum precession orbit, but without any spinning. As the shaft doesn't spin, the sensor is always facing to the same angular portion of the cylindrical surface. Thus, facing different angular positions of the shaft implies different measurements, due to the small imperfections in the cylindrical surface. This fact is taken into account in the processing procedure of raw signals to get maximum eccentricity. As this error is related with surface imperfections it is of the same magnitude like the error measured in Figure 9. Figure 10 shows the results of a maximum eccentricity test for different initial angular position of the shaft. 


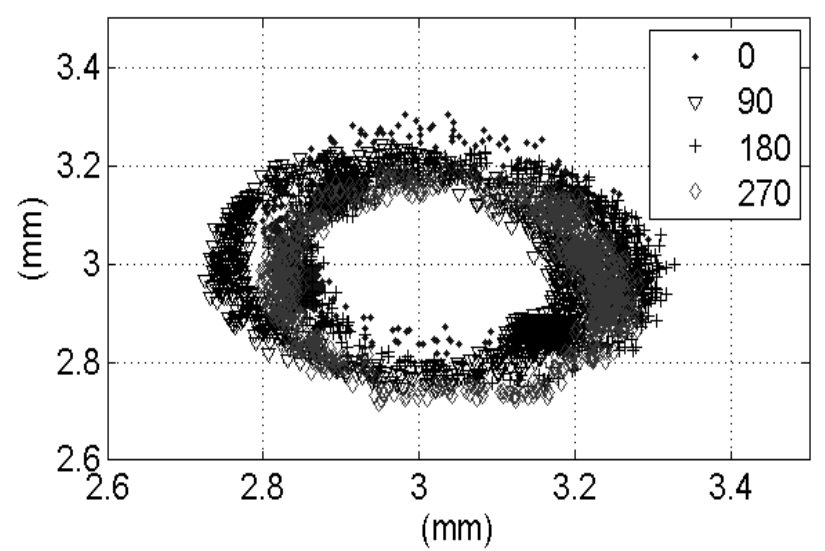

Figure 10 Maximum eccentricity measured with the infrared light diode sensors

\subsection{Data processing for synchronous and sub-synchronous shaft motion determination}

Data processing was used for identifying the synchronous and sub-synchronous shaft motion. The identification of the physical phenomena by means of time-frequency studies has been used successfully in the past, examples are: variation of the pressure in common rail based in Short Time Fourier Transform (STFT) [28], fuel delivery [27], and turbocharger instantaneous speed frequency both based in Discrete Fourier Transform (DFT) [29]. In this paper, a STFT was used as data processing tool. A Hamming window $(w)$ of length $2^{\wedge} 13$ was used (i.e. $81.9 \mathrm{~ms}$ ), but the signal was zeropadded for performing the discrete time Fourier transform with $n f f t=2 \wedge 16$ samples. Since the sampling frequency $(f s)$ was set to $100 \mathrm{kHz}$, this provided a frequency resolution $(\Delta f)$ of $1.53 \mathrm{~Hz}$. On the other hand, the window was shifted in time with an overlap (ov) of 7447 and therefore with an associated time resolution $(d t)$ of $7.5 \mathrm{~ms}$. These calculations have been performed using equations from (1) to (3).

$$
\begin{aligned}
& \Delta f=\frac{f s}{n f f t}=1,53 \mathrm{~Hz} \\
& o v=0,9091 * w=7447 \\
& d t=\frac{(w-o v)}{f s}=7,5 \mathrm{~ms}
\end{aligned}
$$

Where:

- $\Delta f \quad=$ frequency resolution $(\mathrm{Hz})$.

- $f_{s} \quad=$ sampling frequency $(\mathrm{Hz})$.

- $n f f t=$ number of fast fourier transform samples (-). 
- ov = overlap (-)

- $w \quad=$ Hamming window length (-)

- $d t \quad=$ time resolution (s)

Such parameters were defined after several parametrical studies using the measured data; the final definition was done according to a trade-off considering time resolution, frequency resolution, short-time segmentation (which allows to detect abrupt changes since the signal is not averaged), and computational burden.

Once the STFT was computed, a post-processing is used for the determination of the main frequencies of the shaft motion. In this analysis, only three frequencies are considered to determine the shaft motion, which are the most significant of the motion modes. They are the synchronous frequency and two sub-synchronous frequencies (two main frequencies between the continuous and the shaft speed synchronous frequency). Hence a filter based on the instantaneous turbocharger speed is used. Consequently, an inductive sensor was assembled in the compressor volute to determine the instantaneous frequency of the shaft speed. On the basis of this measurement, the filter subroutine searches a maximum amplitude peak of the STFT signal near to measured shaft speed frequency -turbo speed. Following, an error voltage $(0.02 \mathrm{~V})$ is subtracted from the synchronous peak because of the irregularities in the shape of the cylindrical surface, as it has been already discussed. Finally, the filter subroutine searches for the two higher peaks between the continuous and the synchronous frequency, identifying the two subsynchronous frequencies.

Figure 11 shows a test with the turbocharger shaft speed is near to $110,000 \mathrm{rpm}$ in quasi-steady conditions during $0.1 \mathrm{sec}$. Figure 11a) shows the time frame used to process data and to obtain the STFT signal of this period. Figure 11b) shows the STFT signal of this time frame data. This graph shows two main peaks the first one corresponds to the sub-synchronous frequency and the second one corresponds to the synchronous frequency (1833 Hz, which corresponds to 110,000 rpm).
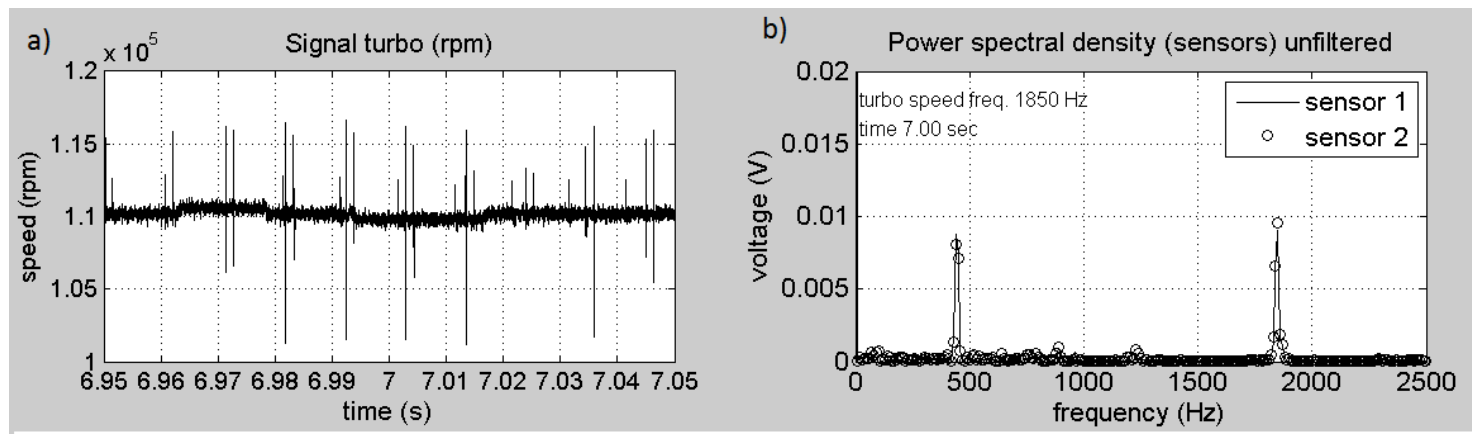
Figure 11 Synchronous and sub-synchronous identification.

Finally, the two peaks of Figure $11 \mathrm{~b}$ ) are used to calculate the $\mathrm{X}$ and $\mathrm{Y}$ position of the shaft, using the calibration curves of the two sensors previously described (Figure 2). On the basis of such filtered STFT and from the application of the inverse STFT the time domain shaft motion can be reconstructed.

\section{APPLICATION OF THE METHODOLOGY AND DISCUSSION OF THE RESULTS}

To illustrate the described technique, a transient test has been done and shaft motion has been measured and calculated considering all the steps from the previously described procedure. This transient test corresponds to accelerate the turbocharger from 30,000 rpm to 120,000 rpm. Figure 12 shows the variation of the turbocharger speed during transient test.

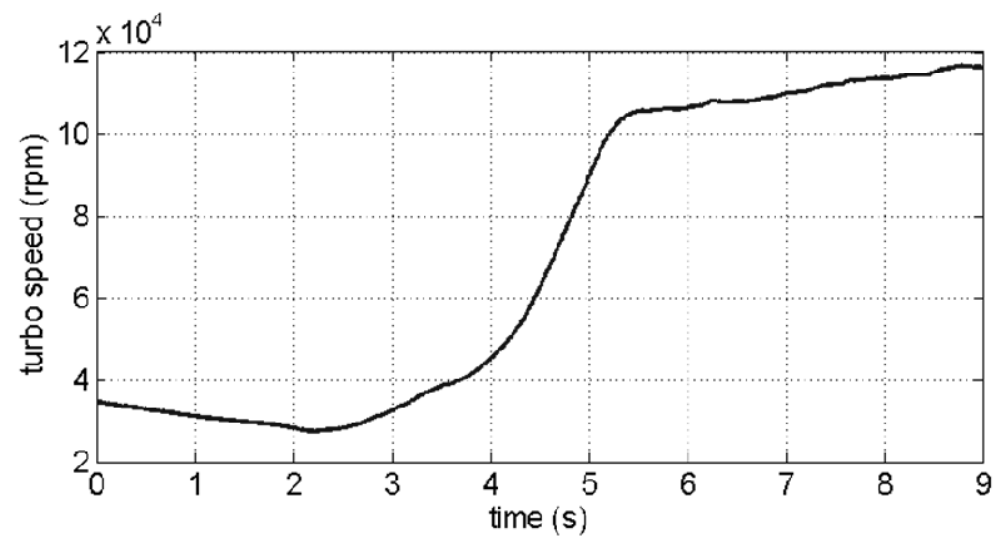

Figure 12 Turbocharger speed during transient test

Figure 13 and Figure 14 show the power spectral density of the STFT analysis for the raw infrared signals of both sensors. Figure 13 and Figure 14 show high amplitude around the synchronous frequencies (syn), which correspond to the speed of the turbocharger shown in Figure 12. Due to the STFT analysis several lines of high amplitudes can also be observed at frequencies multiple of the synchronous frequency. The main sub-synchronous frequency (subsyn) corresponds to the main mode of shaft precession movement. Additionally, different traces in the spectra can be appreciated due to bifurcation in sub-synchronous frequencies. Their definitions are shown from equation (4) to equation (7).

$$
\begin{aligned}
& \text { ss } 1 \approx \text { subsyn } * 2 \\
& \text { ss } 2 \approx s y n-\operatorname{subsyn} \\
& \text { ss } 3 \approx \operatorname{subsyn}+\text { ss } 1-\text { syn } \\
& \text { ss } 4 \approx \text { syn }- \text { ss } 1
\end{aligned}
$$


Where:

- $\operatorname{syn}=$ signal with the same frequency of the shaft.

- $\operatorname{subsyn}=$ signal of the precession movement of the shaft.

- $\quad s s 1, s s 2, s s 4=$ subsynchronous signals corresponds to whirl of the inner oil film.

- $\quad s s 3=$ subsynchronous signals corresponds to whirl of the external oil film.

The turbocharger tested has two full floating radial bearings in the bearing housing. These secondary sub-synchronous amplitudes correspond to the oil whirl/whip phenomena and the movements of the full floating bearings when the turbocharger speed is higher than 40,000 rpm approximately. These motions of the full floating bearing also have been described by other authors [30].

The high amplitudes observed at $1750 \mathrm{~Hz}$ approximately in the case of sensor 1 (Figure 13) and about $600 \mathrm{~Hz}$ in the case of sensor 2 (Figure 14) are due to noise from electromagnetic fields in the electronic components of the sensors (noise).

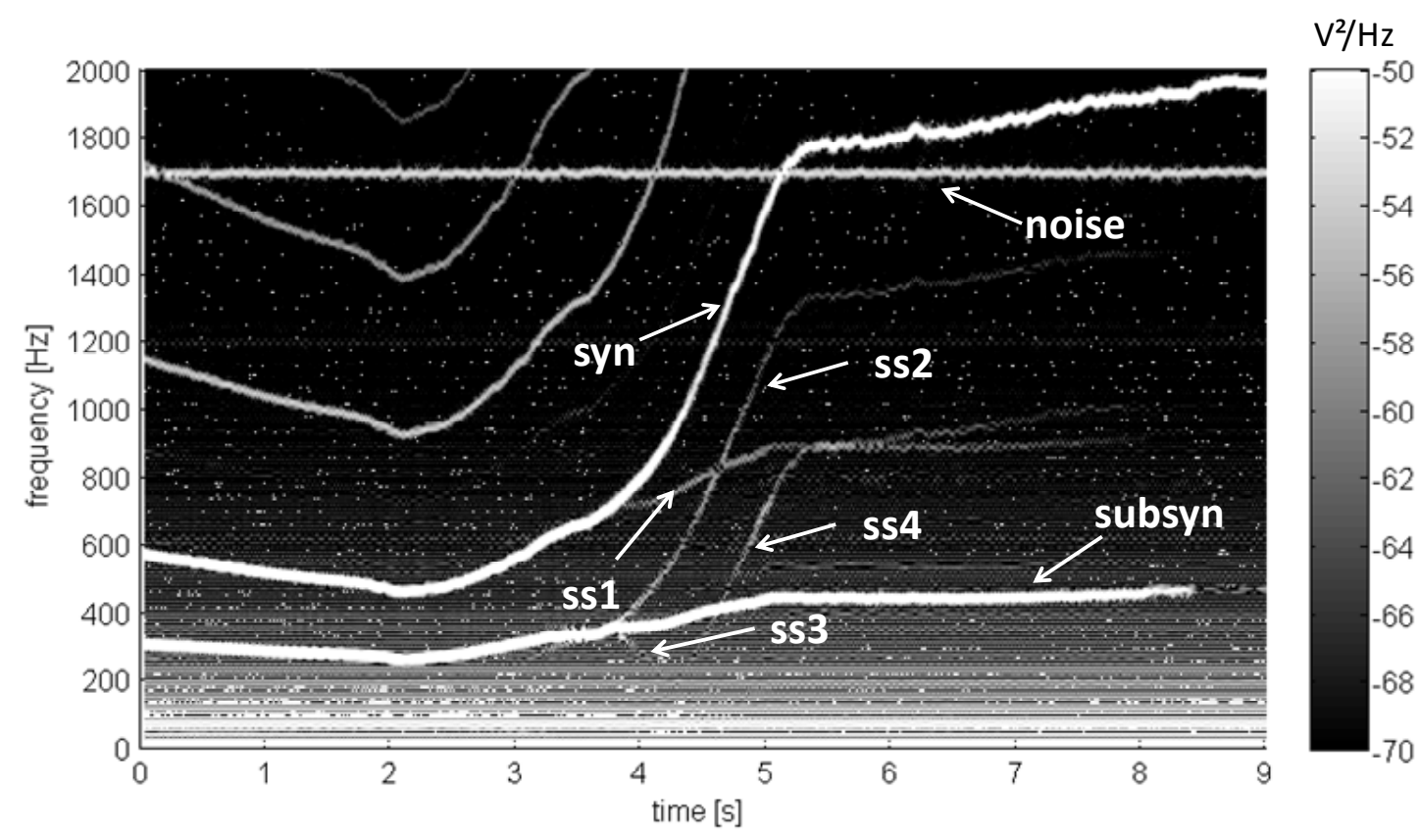

Figure 13 Power Spectral Density Sensor 1 


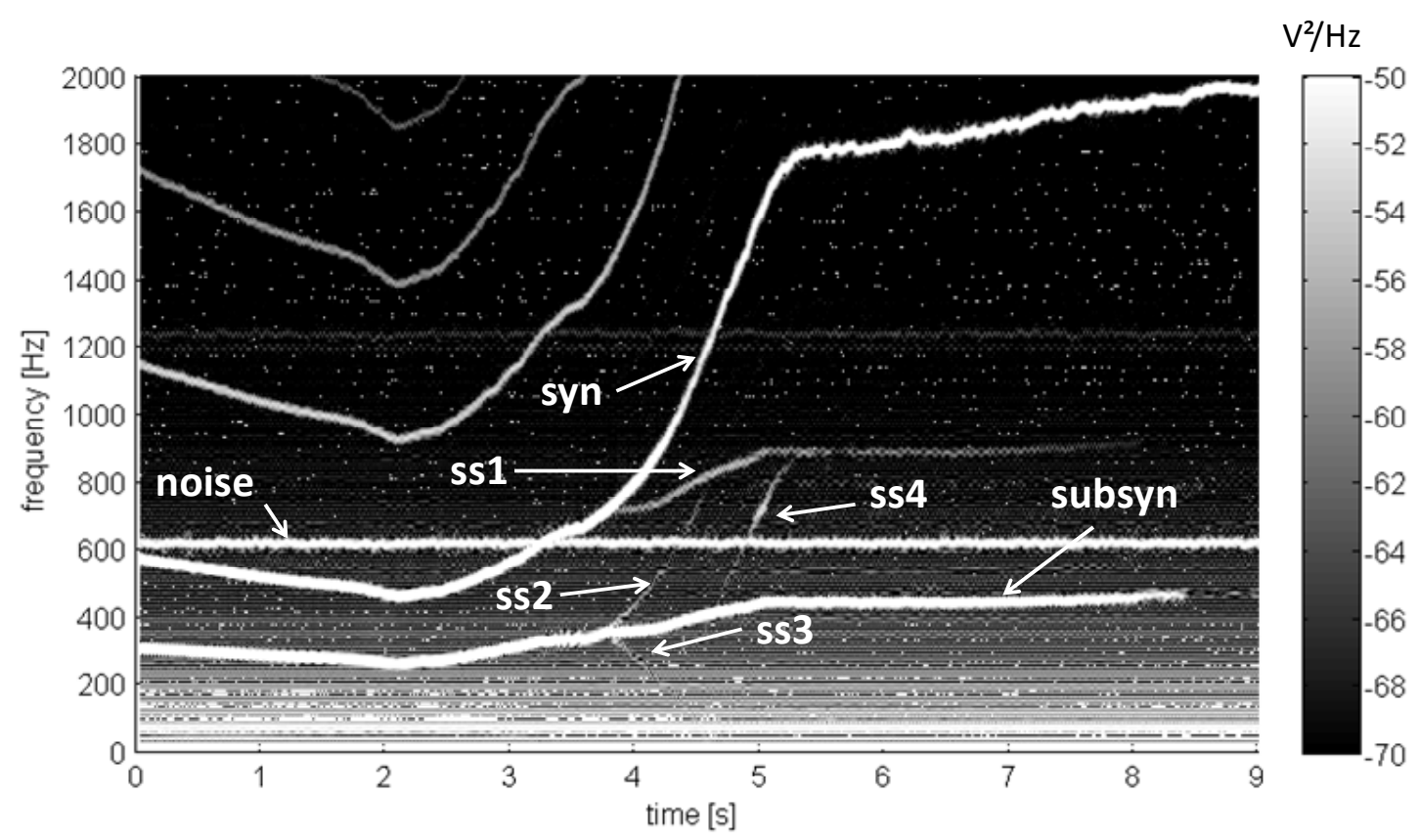

Figure 14 Power Spectral Density Sensor 2

As an example, Figure 15 shows different time frames of this test: column (a) of Figure 15 corresponds to the time frame from $1.85 \mathrm{~s}$ to $1.95 \mathrm{~s}$, column (b) of the figure correspond to the time frame from the $4.55 \mathrm{~s}$ to $4.65 \mathrm{~s}$, and column (c) of the figure correspond to the time frame from $6.55 \mathrm{~s}$ to $6.65 \mathrm{~s}$. All these frames correspond to the transient test represented in Figure 12.

Row (1) of Figure 15 shows the variation of the turbocharger speed during this transient test (light line), and the processed time window (dark segment).

Row (2) of Figure 15 shows the STFT raw signals from both sensors. These charts show some peaks that correspond to signal errors. Nevertheless, relevant peaks are quite evident, i.e.: the synchronous frequency peaks $-480 \mathrm{~Hz}$ at column (a), $1170 \mathrm{~Hz}$ at column (b) and $1810 \mathrm{~Hz}$ at column (c)-, multiples of synchronous frequency and the sub-synchronous peaks. At low turbocharger speeds (lower than 40,000 rpm approximately) the sub-synchronous frequency is near the half of the synchronous, while at high turbocharger speeds (higher than 40,000 rpm approximately) the main sub-synchronous frequency is lower than the half of the synchronous and new subsynchronous frequencies it appear, as Figure 13 and Figure 14 show.

Row (3) of Figure 15 shows the STFT filtered signals of the two sensors according to the method previously described. Filtered signals show just two peaks at columns (a) and (b), i.e.: the two highest peaks of sub-synchronous frequency; due to the synchronous peak being eliminated by subtracting the $0.02 \mathrm{~V}$ corresponding to the 
shape error in the cylindrical nut). At column (c) and about 110,000 rpm synchronous frequency is still visible.

Finally, row (4) in Figure 15 shows the shaft movement graphs. These graphs show a central ellipse with a diameter of $0.15 \mathrm{~mm}$ approx., which is the combination of the filtered signals of the two sensors. It shows that at high speed the shaft movement describes a smaller ellipse than at low speed. This behaviour is coherent with the hydrodynamic lubrication theory [31]. Moreover, row (4) graphs show the combination of the raw signals from the two sensors; it is a light gray shape of approximately 0.3 mm diameter at column (a) and $0.2 \mathrm{~mm}$ diameter at columns (b) and (c). These bottom graphs also show the maximum eccentricity as the black dots with approximately 0.5 $\mathrm{mm}$ in diameter. The shaft motion is located at the bottom of the center of these maximum eccentricity points as the hydrodynamic lubrication theory also predicts [31]

(1)

(a)

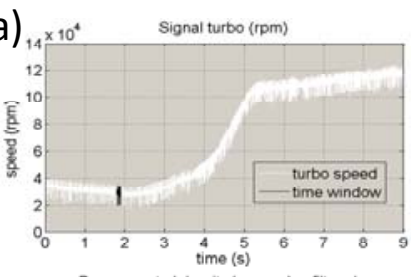

(2)

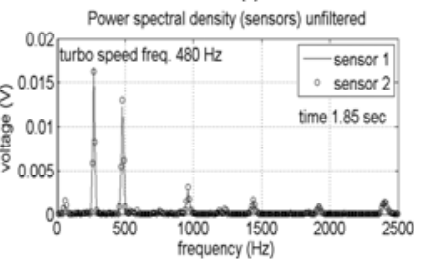

(3)

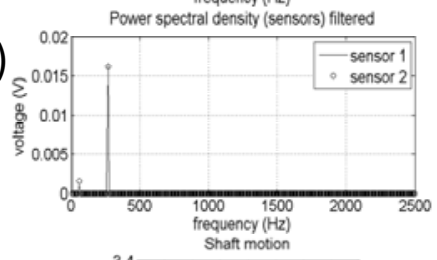

(4)

(a)

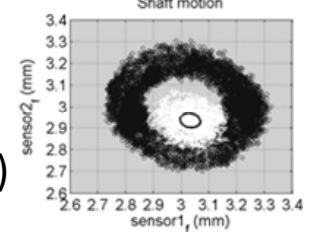

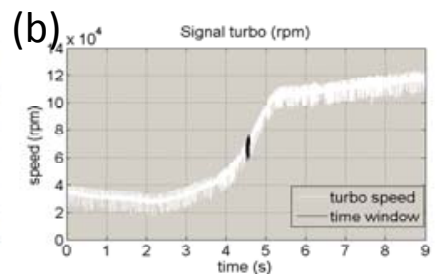
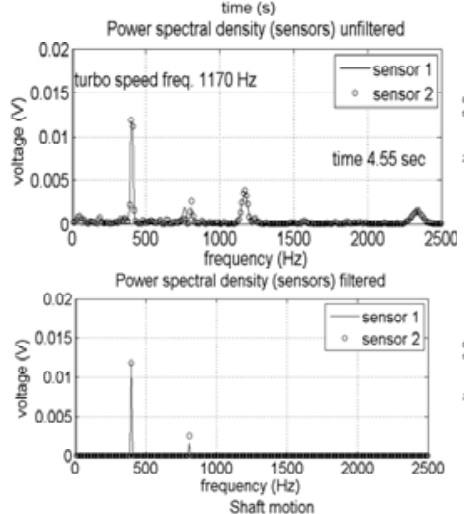

(b)

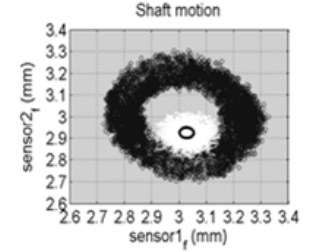

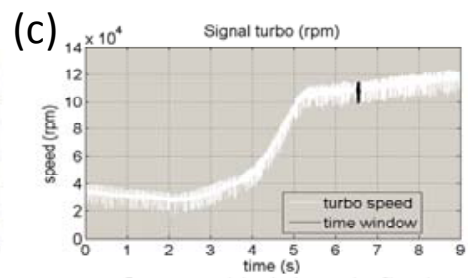

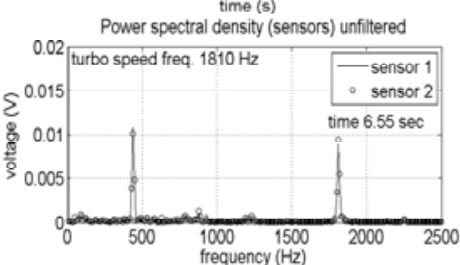

Power spectral density (sensors) unfitered

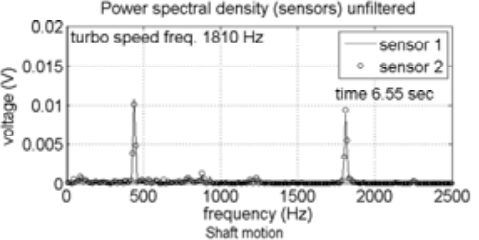

(3)

(c)

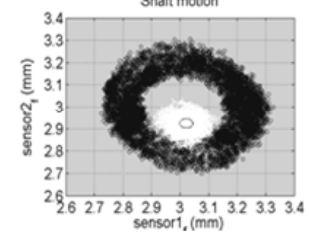

Figure 15 FFT signal spectral in different time frames.

In order to represent the evolution in time of these shaft movement orbits in a 2-D graph, the dimensionless diameters of the shaft movement graphs (raw (4) at Figure 15) in all the time frames have been represented in Figure 16. The different diameters have been normalized with the maximum eccentricity diameter. This maximum eccentricity diameter has been calculated as twice the distance between the centre of gravity of all the maximum eccentricity points and the most distant point to this centre of gravity. The thick continuous black line in Figure 16 is the turbo speed, the dashed black line is the 
maximum normalized eccentricity, the continuous dark gray line is the unfiltered normalized sensors diameter and the continuous light gray line is the filtered normalized sensors diameter.

Figure 16 shows clearly two main types of shaft motion behaviour:

- The first one appears when the turbocharger is rotating at low speeds. From 0 to $4 \mathrm{~s}$ approximately, the shaft movement presents high eccentricities and it corresponds to the time period when the full floating bearings are stopped. The unfiltered shaft movement is about 0.45 times the maximum eccentricity and filtered shaft movement is approx. 0.15 times the maximum eccentricity.

- The second type of behaviour appears at higher turbocharger speeds. From 4 to $9 \mathrm{~s}$, the turbocharger speed is varying and it corresponds to the time period when the full floating bearings are in movement. When it arrives to $120000 \mathrm{rpm}$ the unfiltered and the filtered shaft movement decrease very much. For the studied case, to 0.25 times the maximum eccentricity for the unfiltered movement and to near 0 for the filtered movement.

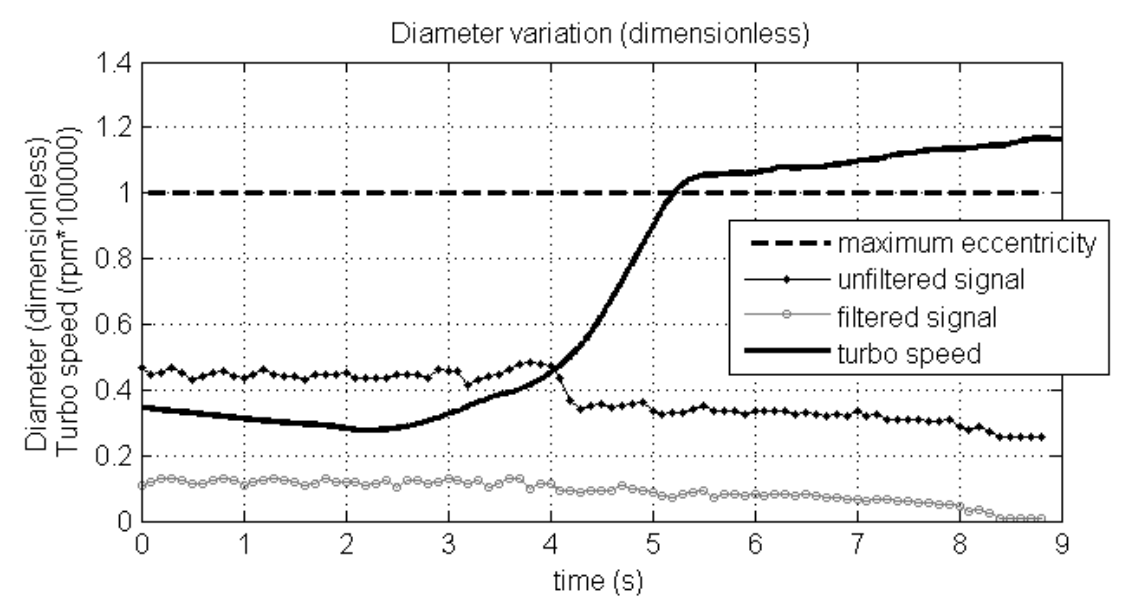

Figure 16 Shaft motion dimensionless evolutions

\section{CONCLUSIONS}

This paper analyses a new procedure for measuring the precession movement of a small turbocharger shaft by means of infrared light diode sensors. The infrared sensors are commonly used to measure this movement in big turbine shafts, but they have not been used in small turbochargers due to the requirements of space availability to install the sensors and the necessary modifications of the shaft to minimize the measurement errors.

In order to adapt this technique to small turbochargers, this paper proposes a methodology for the determination of the shaft motion based on using a modified nut on 
the compressor eye. Specific operations have been described in order to minimize the effect of the following error sources:

- Errors due to the measuring instrument (alignment error, sensor wear error and surface colour error). In order to minimize these errors the calibration of the sensors has to be done with the sensors assembled to the turbocharger and placed in their measurement position. A matte white surface colour has been found optimum to reflect the infrared light maximizing the precision and the repetitiveness of the measurement technique.

- Errors due to ambient sources (errors of external light sources, errors of electromagnetic fields and errors of temperature variations). Sample tests have been done previously to the test in order to use them like a pattern and subtract the errors due to electromagnetic fields and temperature corrections.

- Errors due to the geometric tolerance (deformation error and shape imperfections error). Sample tests have been done in order to use them like a pattern and subtract the errors due to the imperfections in the cylindrical shape of the nut.

Data have been processed using a STFT, which allows detecting the main contributors to the shaft motion. Signal frequency content is filtered according to specific band-pass filters based on the identification of the synchronous and sub-synchronous frequencies, whose contents are corrected for accounting the different error sources.

Applying the previous corrections and the methodology defined, the turbocharger shaft position may be estimated even in transient conditions. This estimation has a good correlation with the shaft motion defined in the bibliography.

Finally, on the one hand the main advantages of this infrared light diode sensor technique are: the shaft position is instantaneously recorded with a high frequency acquisition data (good resolution during transient measurements) and the sensors are far enough from the compressor eye to allow using them even in destructive tests. On the other hand, the main disadvantages are the intrusive mounting (a big diameter nut is necessary to avoid scattering in light reflection) and it does not provide direct observation of the phenomena (poorer understanding than other techniques [10]).

\section{ACKNOWLEDGMENTS}

This work has been partially supported by the Spanish Ministerio de Ciencia e Innovación through grant number DPI2010-20891-C02-02.

This research has been partially supported by Ministerio de Ciencia e Innovación trough Project TRA2010-16205 $\mu$ Diesel.

This research has been partially supported by "Programa de Desarrollo del Talento Humano de la Secretaría Nacional de Educación Superior, Ciencia, Tecnología e Innovación del Gobierno Ecuatoriano”. 


\section{REFERENCES}

[1] Kenji Morita, Automotive power source in 21st century. JSAE Review 24 (2003) 3 - 7.

[2] Murat Karabektas, The effects of turbocharger on the performance and exhaust emissions of a diesel engine fuelled with biodiesel. Renewable energy 34 (2009) 989-993.

[3] Osman Akin Kutlar, Hikmet Arslan, Arper Tolga Calik. Methods to improve efficiency of four stroke, spark ignition engines at part load. Energy Conversion and Management 46 (2005) 3202-3220.

[4] Christian Berggren, Thomas Magnusson, Reducing automotive emissions - The potentials of combustion engine technologies and the power of policy. Energy Policy 41 (2012) 636-643.

[5] Galindo, J., Luján, J.M., Serrano, J.R., Dolz, V., Guilain, S.Design of an exhaust manifold to improve transient performance of a high-speed turbocharged diesel engine (2004) Experimental Thermal and Fluid Science, 28 (8), pp. 863-875.

[6] Nazih N. Bayomia, Rafea M. Abd El-Maksoudb. Two operating modes for turbocharger system. Energy Conversion and Management 58 (2012) 59 - 65.

[7] M. Tancrez, J. Galindo, C. Guardiola, P. Fajardo, O. Varnier, Turbine adapted maps for turbocharger engine matching. Experimental and Fluid Science Volume 35, Issue 1, January 2011, Pages $146-153$.

[8] Galindo, J., Luján, J.M., Serrano, J.R., Dolz, V., Guilain, S. Description of a heat transfer model suitable to calculate transient processes of turbocharged diesel engines with onedimensional gas-dynamic codes (2006) Applied Thermal Engineering, 26 (1), pp. 66-76.

[9] Serrano, J.R., Tormos, B., Gargar, K.L., Bouffaud, F. Study of the effects on turbocharger performance generated by the presence of foreign objects at the compressor intake (2013) Experimental Techniques, 37 (2), pp. 30-40.

[10] JV Pastor, JR Serrano, V Dolz, MA López. Study of turbocharger shaft motion by means of non-invasive optical techniques. Application to the behaviour analysis in turbocharger lubrication failures. Mechanical Systems and Signal Processing 32 (2012) 292-305.

[11] Deligant, Podevin, Descombes. Experimental identification of turbocharger mechanical friction losses. Energy 39 (2012) 388 - 394.

[12] S.A.A. Hosseini, S.E. Khadem, Free vibrations analysis of a rotating shaft with nonlinearities in curvature and inertia. Mechanism and Machine Theory 44 (2009) 272 - 288.

[13] L. Tian, W.J. Wang, Z.J. Peng, Effects of bearing outer clearance on the dynamic behaviours of the full floating ring bearing supported turbocharger rotor. Mechanical Systems and Signal Processing 31 (2012) 155-175. 
[14] Kui Jiao, Harold Sun, Xianguo Li, Hao Wu, Eric Krivitzky, Tim Schram, Louis M. Larosiliere. Numerical simulation of air flow through turbocharger compressors with dual volute design. Applied Energy 86 (2009) 2494 - 2506.

[15] Philippe Moulin, Jonathan Chauvin, Modeling and control of the air system of a turbocharged gasoline engine. Control Engineering Practice 19 (2011) 287 - 297.

[16] L. Tian, W.J. Wang, Z.J. Peng, Dynamic behaviours of a full floating ring bearing supported turbocharger rotor with engine excitation. Journal of Sound and Vibration. Volume 330, Issue 20, 26 September 2011, Pages 4851-4874.

[17] Bernhard Schweizer., Mario Sievert. Nonlinear oscillations of automotive turbocharger turbines. Journal of Sound and vibration 321 (2009) 955 - 975.

[18] Chan-Jung Kim, Yeon June Kang, Bong-Hyun Lee, Hyeong-Joon Ahn, Determination of optimal position for both support bearing and unbalance mass of balance shaft. Mechanical and Machine Theory 50 (2012) 150 - 158.

[19] R. Gordon Kirk, Ali A. Alsaeed, Induced unbalanced as a Method for imporving the dynamic stability of high-speed Turbochargers. International Journal of Rotating Machinery. Volume 2011 (2011), Article ID 952869, 9 pages doi:10.1155/2011/952869.

[20] Bernhard Schweizer, Total instability of turbocharger rotors-Physical explanation of the dynamic failure of rotors with full-floating ring bearings. Journal of sound and vibration 328 (2009) 156-190.

[21] Steve Rothberg, John Bell, On the application of laser vibrometry to translational and rotational vibration measurements on rotating shafts. Measurement 35 (2004) 201 - 210.

[22] P. Günther, F. Dreier, T. Pfiser, J. Czarske, T. Haupt, W. Hufenbach, Measurement of radial expansion and tumbling motion of a high-speed rotor using an optical sensor system. Mechanical Systems and Signal Processing (2010) doi: 10.1016/j.ymssp.2010.08.005

[23] Asmita G. Fulzele, V.G. Arajpure, P.P. Holay, N.M. Patil, Condition monitoring of shaft of single-phase induction motor using optical sensor. Mechanical Systems and Signal Processing 29 (2012) $428-435$

[24] M Zielinski and G Ziller, Noncontact vibration measurements on compressor rotor blades. Measurement Science and Technology 11 (2000) 847-856.

[25] Andreas von Flotow, Mathieu Mercadal, Peter Tappert, Health Monitoring and Pronogstics of Blades and Disks with Blade Tip Sensors. 0-7803-5846-5/00/\$10.00@2000 IEEE.

[26] S. Heath and M. Imregun, An improved single-parameter tip-timing method for turbomachinery blade vibration measurements using optical laser probes. International Journal of Mechanical Sciences Vol 38, No. 10, pp. 1047-1058, 1996. 0020-7403(95)001166

[27] Macián V., Luján J.M., Guardiola C., Perles A., A comparison of different methods for fuel delivery unevennes detection in Diesel engines. Mechanical systems and Signal Processing 20 (8, pp. 2219-2231), 2006 
[28] Payri F., Luján J.M., Guardiola C., Rizzoni G., Injection diagnosis through common-rail pressure measurement. Proceedings of the Institution of Mechanical Engineers, Part D: Journal of Automobile Enginnering, Volume 220, Issue 3, 2006, Pages 347-357

[29] Macián V., Luján J.M:, Guardiola C., Yuste P., DFT-Based Controller for Fuel Injection Unevenness Correction in Turbocharged Diesel Engines .. IEEE Transactions on control systems technologyVol 14, No 5, September 2006.

[30] Bernhard Schweizer, Dynamics and stability of turbocharger rotors. Archive of Applied Mechanics (2010) 80: 1017-1043 DOI 10.1007/s00419-009-0331-0

[31] Yukio Hori, Hydrodynamic Lubrication. ISBN-10 4-431-27898-2 Springer-Verlag Tokyo Berlin Heidelberg New Tork. 